Int. J. Electrochem. Sci., 11 (2016) $6009-6022$

\title{
Sensitively Voltammetric Determination of Vanillin with a Molecularly Imprinted Ionic Liquid Polymer-Carboxyl Single- Walled Carbon Nanotubes Composite Electrode
}

\author{
Wenhui Wu, Hao Wang, Lite Yang, Faqiong Zhao, Baizhao Zeng ${ }^{*}$
}

Key Laboratory of Analytical Chemistry for Biology and Medicine (Ministry of Education), College of Chemistry and Molecular Sciences, Wuhan University, Wuhan 430072, Hubei Province, P. R. China *E-mail: bzzeng@whu.edu.cn

doi: 10.20964/2016.07.03

Received: 27 March 2016 / Accepted: 5 May 2016 / Published: 4 June 2016

\begin{abstract}
A molecularly imprinted ionic liquid polymer-carboxyl single-walled carbon nanotubes composite coated glassy carbon electrode (MIP-SWNTs-COOH/GCE) was prepared. The MIP was synthesized by using vanillin (VA) as template, hydrophilic ionic liquid 1-( $\alpha$-methylacrylate)-3-allylimidazolium bromide as functional monomer and ethyleneglycol dimethacrylate as crosslinker. The MIP was watercompatible and had porous structure and large surface. The ionic liquid and VA could interact through $\pi-\pi$ and hydrogen bonds, thus the imprinted sites possessed good specific recognization ability. When it was loaded on SWNTs-COOH film, the resulting electrode exhibited highly selective and sensitive response to VA in aqueous solution. After optimizing the conditions, linear response ranges of 0.4-8 and $10-140 \mu \mathrm{M}$ with sensitivities of $178 \mu \mathrm{A} / \mu \mathrm{M} \mathrm{cm}{ }^{2}$ and $8.1 \mu \mathrm{A} / \mu \mathrm{M} \mathrm{cm}{ }^{2}$ were obtained. The electrode was successfully applied to the detection of VA in biscuit, soybean milk powder and vanilla tea, and the recoveries for standards added were $94-107 \%$.
\end{abstract}

Keywords: Vanillin; Molecularly imprinted polymer; Single-walled carbon nanotubes; Ionic liquid polymer; Electrochemical sensor

\section{FULL TEXT}

(C) 2016 The Authors. Published by ESG (www.electrochemsci.org). This article is an open access article distributed under the terms and conditions of the Creative Commons Attribution license (http://creativecommons.org/licenses/by/4.0/). 